
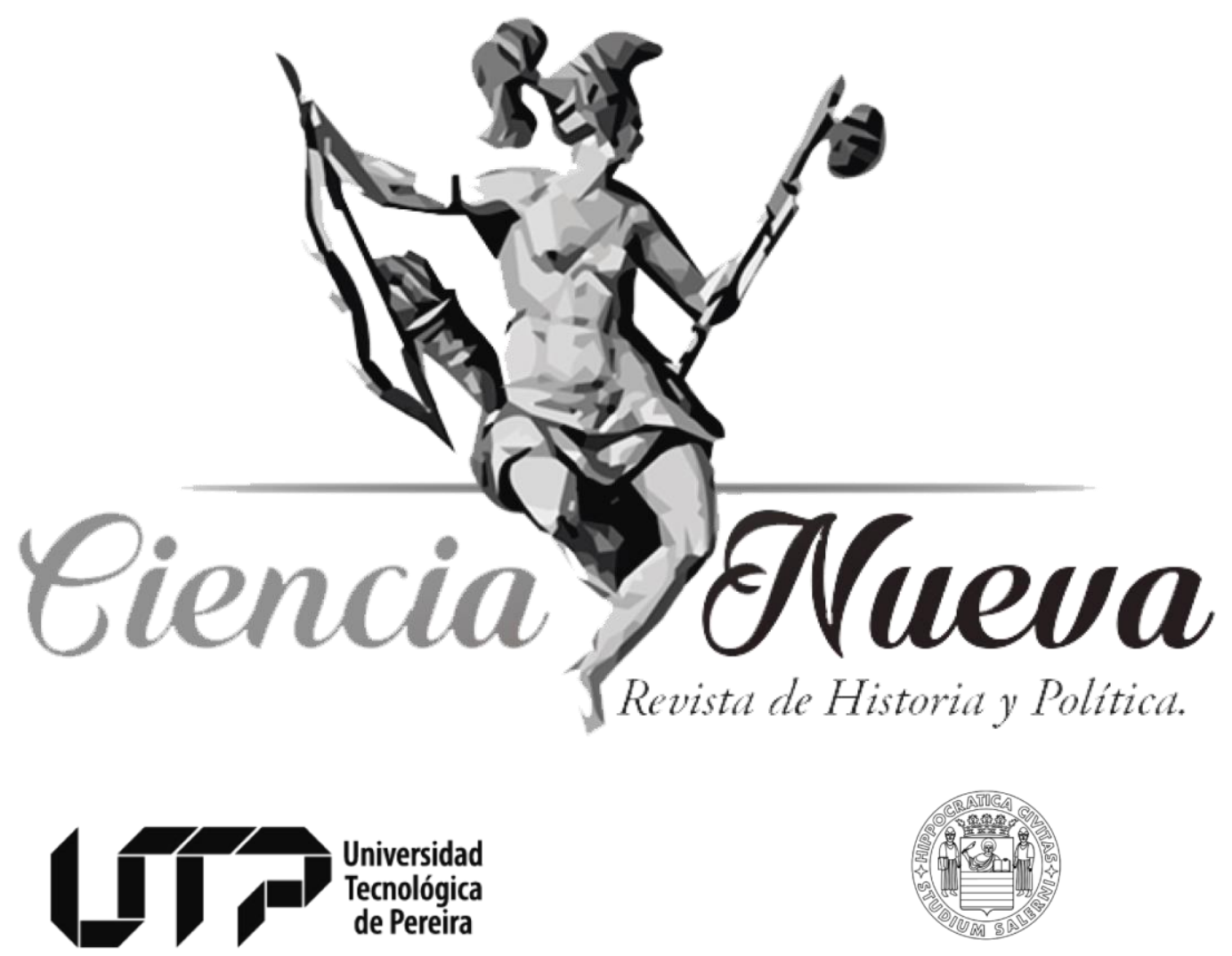

UNIVERSITÀ DEGLI STUDI DI SALERNO

Maestría en Historia

Maestría en Ciencia Política

ESTUDIOS HISTÓRICOS

\title{
ACERCA DEL OFICIO DEL HISTORIADOR O DE UN DIÁLOGO Y EXAMEN SOBRE SU PRÁCTICA
} ABOUT THE HISTORIAN'S OFFICE OR A DIALOGUE AND EXAM ON HIS PRACTICE DOI: https://doi.org/10.22517/25392662.20941 Álvaro Acevedo Tarazona y Sebastián Vélez Restrepo pp. 41-57

Vol. 3 Núm. 2 | Julio-Diciembre de 2019

Pereira, Colombia 


\title{
ACERCA DEL OFICIO DEL HISTORIADOR O DE UN DIÁLOGO Y EXAMEN SOBRE SU PRÁCTICA*
}

\author{
ABOUT THE HISTORIAN'S OFFICE OR A DIALOGUE AND EXAM ON HIS PRACTICE
}

\author{
Álvaro Acevedo Tarazona** \\ acetara@uis.edu.co
}

ORCID: http://orcid.org/0000-0002-3563-9213

Sebastián Vélez Restrepo ${ }^{* * *}$
sebasver25@gmail.com

ORCID: http://orcid.org/0000-0001-8526-0327

$\begin{array}{cl}\text { Recibido: } & \text { 08 de noviembre de } 2018 . \\ \text { Revisado: } & 05 \text { de marzo de } 2019 . \\ \text { Aceptado: } & 11 \text { de marzo de } 2019 . \\ \text { Publicado: } & 30 \text { de diciembre de } 2019 .\end{array}$

\section{Resumen}

A manera de un diálogo historiográfico se superponen y contrastan un conjunto de reflexiones sobre el oficio del historiador. Una práctica que tiene como telón de fondo un permanente diálogo con la investigación. Para ello se traen a discusión reflexiones disciplinarias e implicaciones acerca del uso y análisis de las fuentes para la historia, de la historiografía como representación y conocimiento de lo histórico. En particular, se espera que este diálogo enriquezca las prácticas del oficio y las propias reflexiones sobre la disciplina.

Palabras clave: enseñanza de la historia, fuentes de información, historia, historiografía.

\section{Abstract}

In the manner of a historiographical dialogue, a set of reflections on the historian's craft are superimposed and contrasted. A practice that has as a backdrop an ongoing dialogue with research. For this, disciplinary reflections and implications about the use and analysis of sources for history, of historiography as representation and knowledge of history are brought to the discussion. In particular, this dialogue is expected to enrich the practices of the trade and the reflections on the discipline itself.

Keywords: teaching of history, information sources, history, historiography.

\footnotetext{
* Este documento respeta las directrices y normas dispuestas en la Declaración de Ética de Publicación de Ciencia Nueva, Revista de Historia y Política. Esta declaración puede consultarse en la página web de la revista: http://revistas.utp.edu.co/index.php/historia

** Historiador y magíster en Historia de la Universidad Industrial de Santander, especialista en Docencia en Historia y Cultura de América Latina y magíster en Historia de América: De la Ilustración al Mundo Contemporáneo de la Universidad Pablo de Olavide (Sevilla, España), doctor en Historia de la Universidad de Huelva (España) y posdoctorado en Ciencias de la Educación de la Universidad Pedagógica y Tecnológica de Colombia-RUDECOLOMBIA. Profesor titular de la Universidad Industrial de Santander y director del Grupo de Investigación "Políticas, Sociabilidades y Representaciones Histórico-Educativas (PSORHE)".

*** Sociólogo de la Universidad Nacional de Colombia, sede Bogotá y magíster en Desarrollo Educativo y Social de la Universidad Pedagógica Nacional. Profesor de cátedra y candidato a doctor en Historia de la Universidad Industrial de Santander.
} 


\title{
Introducción
}

$\mathrm{E}$ n este artículo se examinan un conjunto de reflexiones sobre el oficio del historiador. En particular, se espera que el análisis de dichos trabajos contribuya a complejizar la mirada sobre el quehacer del historiador y enriquezca las prácticas formativas e investigativas en las escuelas y departamentos de historia y en las facultades universitarias vinculadas directa o indirectamente con la enseñanza de la historia. Aunque en el marco del artículo se entiende el oficio del historiador como una tarea compleja en la cual se ponen en juego concepciones sobre qué es, de qué se trata, cómo procede y para qué sirve la historia ${ }^{1}$, en las siguientes páginas, y solo con fines expositivos, se analizan de manera independiente cuatro aspectos centrales del oficio del historiador: I. La delimitación de la investigación. II. El trabajo de la búsqueda, la crítica y la interpretación de fuentes. III. La definición de los alcances, los límites y los usos de la investigación histórica. IV. La reflexión sobre la naturaleza del conocimiento histórico. Finalmente, en el último apartado, se recogen las principales conclusiones de los apartados precedentes y se presentan algunas reflexiones sobre la vigencia y funciones sociales de la historia en el siglo XXI.

\section{La historiografía como acto de delimitación}

Entre quienes se dedican a la investigación histórica, hay un consenso más o menos general en torno a una idea según la cual la historiografía nace de un acto de delimitación del acontecer para hacerlo presente con palabras. Con frecuencia, para llegar a buen puerto, el historiador elige una temática, selecciona unidades de análisis, establece límites geográficos para su estudio, periodiza, selecciona métodos y técnicas para trabajar con el material empírico y, en ocasiones, define a qué público estará dirigido su trabajo. Krzysztof Pomian señala lo siguiente sobre este particular:

\begin{abstract}
Los historiadores eligen los objetos que les interesan y, por lo tanto, los documentos que estudian y que siempre son sólo una parte del conjunto virtualmente infinito de documentos susceptibles de ser pertinentes. Eligen el enfoque que dan a estos documentos, el tratamiento que les aplican y la manera en que interpretan sus resultados. Eligen unas explicaciones y no otras, así como los procedimientos literarios que aplican. Todas esas opciones proceden de consideraciones muy diversas. Pero, en definitiva, sólo se reconocen como legítimas cuando, al tiempo que hacen que progresen nuestros conocimientos, pueden ser explicadas y estar codificadas para que cualquier historiador que trabaje sobre un tema análogo pueda replicarlas ${ }^{2}$.
\end{abstract}

En este proceso de delimitación de la investigación histórica influye, en primer término, el enfoque o punto de análisis con el cual el historiador se enfrenta al estudio del acontecer. Por un lado, la historia (como res gestae) denota el devenir en que el ser humano se realiza, lo acontecido, las cosas sucedidas. Por otro lado, la historia (como rerum gestarum) denota el conocimiento de ese devenir como relación de las cosas sucedidas. Por ello, en adelante, se usará la palabra "historia" para hacer referencia a lo acontecido y la palabra "historiografía" para referirnos al conocimiento producido sobre lo acontecido" ${ }^{3}$.

\footnotetext{
${ }^{1}$ Robin George Collingwood, Idea de la historia (México: Fondo de Cultura Económica, 1952), 17-18.

${ }^{2}$ Krzysztof Pomian, Sobre la historia (Madrid: Ediciones Cátedra, 2007), 214.

${ }^{3}$ Para profundizar sobre la distinción entre historia e historiografía consultar: Julio Aróstegui, La investigación histórica: teoría y método (Barcelona: Crítica, 1995).
} 
En líneas generales, quienes se dedican a la producción historiográfica reconocen que la historia como disciplina es una obra colectiva y que el trabajo del historiador está siempre inscrito en un marco historiográfico, en un contexto en el cual el historiador tiene a su disposición un conjunto de formas siempre heterogéneo, aunque finito, de hacer historia. En ese orden de ideas, como lo señala Michel de Certeau, una obra de valor en historia generalmente es aquella:

... reconocida como tal por sus iguales. La que puede situarse en un conjunto operatorio. La que representa un progreso con relación al estatuto actual de los objetos y los métodos históricos y que, vinculada al medio en el que se elabora, posibilita, a su vez, nuevas investigaciones. El libro o el artículo de la historia es, a la vez, un resultado y un síntoma de un grupo que funciona como un laboratorio [...] el estudio histórico se vincula al complejo de una fabricación específica y colectiva más bien que ser el efecto de una filosofía personal o la resurgencia de una realidad pasada. Es el producto de un lugar ${ }^{4}$.

En el mismo nivel de reflexión, quienes cultivan la historia como disciplina aceptan, cada vez con más determinación, que la objetividad del trabajo histórico se alcanza fundamentalmente cuando se somete dicho trabajo al juicio de una comunidad de historiadores y no cuando se mantiene una actitud neutral frente a aquello que se estudia. En esos términos, se pide cada vez más al historiador explicitar las condiciones en que su trabajo debe ser juzgado y señalando. Entre otras cosas, cuáles son los supuestos, los alcances y los límites de las investigaciones que realiza ${ }^{5}$. Refiriéndose a este asunto, Jacques Le Goff argumenta que "la objetividad histórica se construye poco a poco, a través de las revisiones incesantes del trabajo histórico, las laboriosas rectificaciones sucesivas, la acumulación de las verdades parciales"6. Argumento que es ratificado por el historiador Krzysztof Pomian cuando expone que "... la historia es selectiva [...] aunque lo sea de una manera distinta que la memoria. Porque el carácter selectivo de la historia puede controlarse y los criterios que esta aplica pueden, hasta cierto punto, hacerse explícitos, lo que permite criticarla"7.

En la delimitación de la investigación histórica influye también el contexto social en el cual vive y reflexiona el historiador. Un número significativo de quienes se dedican a estudiar el acontecer aceptan que toda obra historiográfica nace, de una u otra manera, de un diálogo con un presente, con un presente en el cual, por razones disímiles, adquiere cierta legitimidad el interés por el estudio del acontecer. En esos términos, en alguna medida, la historia es siempre un esfuerzo de autocomprensión, un intento de hacer inteligible cómo hemos llegado a ser lo que somos, y a ese intento se le ha llamado "pasado". Sobre este asunto, Raymond Aron expone:

La historia permanece siempre al servicio de la vida, ya ofrezca unos modelos, juzgue el pasado o sitúe el momento actual en el devenir. La historia expresa un diálogo del presente con lo acontecido (denominado "pasado") en el que el presente toma y conserva la iniciativa ${ }^{8}$.

\footnotetext{
${ }^{4}$ Michel de Certeau, "La operación histórica", en Hacer la historia. Nuevos problemas, comp. por Jacques Le Goff y Pierre Nora (Barcelona: Editorial Laia, 1978), 25-26.

${ }^{5}$ Pomian, Sobre la historia, 61.

${ }^{6}$ Jacques Le Goff, Pensar la historia (Barcelona: Editorial Altaya, 1995), 35.

${ }^{7}$ Pomian, Sobre la historia, 214.

${ }^{8}$ Raymond Aron, Dimensiones de la conciencia histórica (Madrid: Tecnos S.A., 1982), 15.
} 
De la misma manera, Fernand Braudel postula que "de hecho, el historiador no se evade nunca del tiempo de la historia: el tiempo se adhiere a su pensamiento como la tierra a la pala del jardinero". Y Lucien Febvre señala que "lo quiera o no, es en función de sus necesidades presentes como la historia recolecta sistemáticamente, clasifica y agrupa, el acontecer. Es en función de la vida como la historia interroga a la muerte"10.

Finalmente, todo acto de delimitación de la investigación histórica nace de una teoría sobre el tiempo histórico, de un conjunto de supuestos sobre qué es y de qué se trata la historia. Para el historiador, como lo señala magistralmente Marc Bloch, el tiempo es el foco del análisis, el lente a partir del cual se intentan comprender las acciones de los hombres: "El tiempo de la historia, por el contrario, es el plasma mismo donde están sumergidos los fenómenos y es como el lugar de su inteligibilidad"11. En ese orden de ideas, las posibles unidades de análisis del historiador son tan diversas como diversas son las estrategias utilizadas por este para dar cuenta de la temporalidad de los fenómenos que analiza.

Historiadores como Jacques Le Goff insisten, por ejemplo, en que el historiador tiene la responsabilidad de recuperar simultáneamente aquello que hay de singular e irrepetible en los acontecimientos históricos ${ }^{12}$ y aquello que los vincula con otros acontecimientos: las permanencias, las secuencias y los encadenamientos.

... quien escribe está convencido de que el trabajo del historiador tiene como objetivo hacer inteligible el proceso histórico, y que esta inteligibilidad conduce al reconocimiento de regularidad en la evolución histórica [...] Hay que reconocer esas regularidades ante todo dentro de cada una de las series estudiadas por el historiador, que las vuelve inteligibles descubriendo en ellas una lógica ... ${ }^{13}$.

Este interés por dar cuenta de los procesos históricos es compartido también por el historiador inglés E.P Thompson, quien señala que:

Un historiador, en su práctica como tal, es inducido a hacer una suposición provisional de carácter epistemológico: que los datos empíricos que maneja tienen una existencia real (determinante) independiente de su existencia en las formas del pensamiento; que estos datos empíricos dan testimonio de un proceso histórico real; y que este proceso (o alguna intelección apropiada del mismo) constituye el objeto del conocimiento histórico ${ }^{14}$.

Desde otro ángulo, historiadores como Marc Bloch y Fernand Braudel insisten en la importancia de comunicar, en la investigación histórica, de la duración particular de cada uno de los fenómenos estudiados y en la importancia de reconocer que los acontecimientos políticos, económicos, sociales y culturales tienen distintas duraciones. Entre otras cosas, estos autores plantean que, para el historiador:

... el corte más exacto no es forzosamente el que echa mano de la unidad de tiempo más pequeña; si así fuera, habría que preferir no solo el año a la década, sino también el segundo al día. La verdadera exactitud consiste en dejarse guiar, en cada ocasión, por la naturaleza del fenómeno considerado. Porque cada tipo tiene su medida particular y, por así decirlo, su décima específica. Las

\footnotetext{
${ }^{9}$ Fernand Braudel, La historia y las ciencias sociales (Madrid: Alianza, 1970), 97.

${ }^{10}$ Lucien Febvre, Combates por la historia (Barcelona: Ariel, 1982), 245.

${ }^{11}$ Marc Bloch, Apología para la historia o el oficio de historiador (México. Fondo de Cultura Económica, 2001), 58.

12 "Cada hecho histórico acaece sólo una vez y no volverá a producirse". Le Goff, Pensar la historia, 36.

${ }^{13}$ Le Goff, Pensar la historia, 46.

${ }^{14}$ Edward P. Thompson, La miseria de la teoría (Barcelona: Crítica, 1981), 51.
} 
transformaciones de la estructura social, de la economía, de las creencias, del comportamiento mental no pueden plegarse, sin un desafortunado artificio, a un cronometraje demasiado estrecho ${ }^{15}$.

\section{Lo cual ratifica Braudel cuando dice:}

... no existe un tiempo social de una sola y simple colada, sino un tiempo social susceptible de mil velocidades, de mil lentitudes, tiempo que no tiene prácticamente nada que ver con el tiempo periodístico de la crónica y de la historia tradicional ${ }^{16}$. [...] cada actualidad reúne movimientos de origen y de ritmo diferente: el tiempo de hoy data a la vez de ayer, de anteayer, de antaño ${ }^{17}$.

El historiador mexicano Carlos Antonio Aguirre señala, a propósito de esta complejidad temporal, de esta coexistencia de múltiples temporalidades, lo siguiente:

Porque son el anticuario y el coleccionista de antigüedades, los que se ocupan solo del pasado, rompiendo artificialmente una línea temporal que es esencialmente continua, línea que nos demuestra permanentemente que cualquier presente -y por ende, cualquier pasado- no es más que una compleja articulación estratificada de distintos pasados todavía presentes, es decir de diversos hechos y fenómenos históricos que remontan su origen y su vigencia a muy diferentes líneas y magnitudes temporales, magnitudes que incluyen desde el estricto ayer de unos días, semanas o meses, hasta los varios pasados de lustros, décadas, siglos o hasta milenios ${ }^{18}$.

En otro frente, el historiador alemán Reinhart Koselleck propone tomar el cambio histórico como unidad de análisis, como foco de la labor historiográfica. Para ello, formula una teoría de los estratos del tiempo en la que, entre otras cosas, plantea que hay por lo menos tres formas como los seres humanos toman consciencia del cambio histórico: a partir de su experiencia de vida; a partir de la experiencia de sus padres o abuelos (experiencia generacionalmente acumulada) o a partir de la investigación histórica ${ }^{19}$. Sobre la importancia del cambio histórico como unidad de análisis y sobre la importancia de otorgarle relevancia analítica a la forma como las personas experimentan los cambios históricos, Koselleck señala:

Nuestra experiencia específicamente moderna de que no sólo cambian los acontecimientos, sino también los presupuestos de esos acontecimientos, las estructuras mismas -y esto de modo evidente, no sólo retrospectivamente, sino ya en la percepción inmediata-, condujo a un perspectivismo temporal de toda la historia, ahora reflejado conscientemente en los métodos. No solo la recurrente mutabilidad de todas las cosas [...] sino el cambio en tanto tal se convirtió en el gran tema de la historia ${ }^{20}$.

Es decir, que el cambio de experiencia puede llevarse a cabo, según Koselleck, en el largo plazo, de manera muy lenta y sin ser percibido, porque "estos procesos de largo plazo, que actúan en todo conflicto o contribuyen a provocarlo, permanecen presentes como una

\footnotetext{
${ }^{15}$ Bloch, Apología ...,170.

${ }^{16}$ Braudel, La historia ..., 29.

${ }^{17}$ Braudel, La historia..., 76.

${ }^{18}$ Carlos Antonio Aguirre, Antimanual del mal historiador: o ¿cómo hacer hoy una buena historia crítica? (México: Editorial Contrahistorias, 2005), 25-26.

19 "Hay tiempos históricos que sobrepasan la experiencia de los individuos y las generaciones. En este caso se trata de depósitos de experiencia que estaban disponibles antes de las generaciones contemporáneas y que seguirán estando muy probablemente tras las generaciones contemporáneas". Reinhart Koselleck, Los estratos del tiempo: estudios sobre la historia (Barcelona: Paidós, 2001), 41.

${ }^{20}$ Koselleck, Los estratos..., 88.
} 
experiencia de trasfondo, aunque sólo seamos conscientes de ellos gracias a la investigación histórica" ${ }^{21}$.

Este interés por mostrar el cambio histórico, especialmente el interés por dar cuenta de los cambios que acontecen en la larga duración, por los cambios en las estructuras sociales, es compartido por Fernand Braudel ${ }^{22}$. Para este autor, al igual que para Koselleck y Bloch, el historiador tiene que dar parte simultáneamente de los cambios que acontecen tanto en la corta, como en la media y en la larga duración:

...los hombres, incluso los más grandes, no nos aparecen ya tan libres e indeterminados como nuestros predecesores en el oficio histórico; más no por ello disminuye el interés que su vida despierta: más bien al contrario. Y la dificultad no radica en conciliar en el plano de los principios, la necesidad de la historia individual y de la historia social; la dificultad reside en ser capaz de tener sensibilidad para ambas al mismo tiempo y en conseguir apasionarse por una de ellas sin por ello olvidar a la otra ${ }^{23}$.

Es decir, que se falsearía el problema de las causas en historia, si este se redujera solo a un problema de motivos ${ }^{24}$. Los historiadores sociales franceses han llamado también la atención sobre la importancia de focalizar el análisis histórico en los seres humanos, en las actividades que realizan, en sus creencias, en las instituciones que establecen, en los dispositivos tecnológicos que fabrican y, en general, en todo aquello que sirve como huella, como vestigio de su paso por el mundo:

El objeto de la historia es, por naturaleza, el hombre. Mejor dicho: los hombres. Tras los rasgos sensibles del paisaje (las herramientas o las máquinas) tras los escritos en apariencia más fríos y las instituciones en apariencia más distanciadas de quienes las establecieron, la historia quiere captar a los hombres [...] El buen historiador se parece al ogro de la leyenda. Ahí donde olfatea carne humana, ahí sabe que está su presa ${ }^{25}$.

Sin lugar a dudas, el historiador no debe olvidar que la historia es la ciencia del hombre, es la "ciencia del perpetuo cambio de las sociedades humanas, de su perpetuo y necesario reajuste a nuevas condiciones de existencia material, política, moral, religiosa, intelectual" 26 .

Por último, historiadores contemporáneos como Ulrich Gumbrecht y Luis González insisten en la necesidad de estudiar el tiempo en su dimensión sincrónica. Para ellos, el historiador debe fijar su atención en la forma de vida y las costumbres de los hombres del pasado, sin preocuparse por establecer las conexiones de ese pasado con el momento actual. Ya lo indica González, "a la microhistoria le interesa, más que lo que influye o renace, lo que es en cada momento" 27 .

Por su parte, para Gumbrecht:

\footnotetext{
${ }^{21}$ Koselleck, Los estratos..., 53-54.

22 Para Braudel "una estructura es indudablemente un ensamblaje, una arquitectura; pero, más aún, una realidad que el tiempo tarda enormemente en desgastar, en transportar". Braudel, La historia ..., 88.

${ }^{23}$ Braudel, La historia ..., 42-43.

${ }^{24}$ Bloch, Apología..., 177.

${ }^{25}$ Bloch, Apología..., 56.

${ }^{26}$ Febvre, Combates..., 56.

${ }^{27}$ Luis González, Otra invitación a la microhistoria (México D.F.: Fondo de Cultura Económica, 2003 ), 32.
} 
Mucho más importante que la elección de un lapso de tiempo, sin embargo, es la decisión de abstraerse (todo lo que sea posible) de la secuencialidad y causalidad dentro de la reconstrucción historiográfica [...] la suspensión de la secuencialidad surge de la elección de un ángulo específico de la representación histórica. En este caso es la concentración en un año considerado como un entorno, como un mundo dentro del cual vivía la gente ${ }^{28}$.

Así, ante un universo de objetos posibles de estudio, ante a la amplitud o a la escasez de las fuentes, ante a la pluralidad de métodos y técnicas de investigación disponible, el historiador se ve compelido a tomar decisiones, a precisar su tiempo, su campo y su objeto de estudio.

Este ejercicio de delimitación exige también al historiador, como parte de su oficio, problematizar o elaborar el hecho histórico ${ }^{29}$, abordarlo desde una perspectiva teórica que, entre otras cosas, le permita situar los resultados de su investigación en el marco de un debate historiográfico, pues

...el historiador crea sus materiales o los recrea, si se quiere: el historiador no va rondando al azar a través del pasado, como un trapero en busca de despojos, sino que parte de un proyecto preciso en la mente, un problema a resolver, una hipótesis de trabajo a verificar ${ }^{30}$.

Por lo demás, es común encontrar en la producción historiográfica de los historiadores de posguerra lo que Hayden White, siguiendo a Roland Barthes, ha denominado una escritura intransitiva $^{31}$. Un tipo de escritura en la cual los historiadores incluyen, deliberadamente en sus trabajos, reflexiones sobre su práctica historiográfica, explicitando, entre otras cosas, las razones que los motivaron a optar por una determinada forma de hacer historia, a delimitar sus investigaciones de cierta manera, a problematizar los hechos desde un determinado ángulo y a utilizar un andamiaje teórico particular.

\section{Del trabajo con las fuentes}

La mayor parte de quienes se dedican a la investigación en el campo de la historia reconocen que el conocimiento de lo acontecido es un conocimiento indirecto, por huellas. Con fines expositivos y siguiendo un esquema propuesto por Luis González, nos concentramos en este apartado en tres aspectos centrales del trabajo que realiza el historiador con los vestigios del pasado: le heurística, la crítica y la interpretación de fuentes ${ }^{32}$. En términos esquemáticos, la heurística consiste en el punto de vista o enfoque que se asume sobre un problema de investigación y la consecuente búsqueda de las mejores fuentes disponibles. La crítica es la constatación de la autoría, la datación, la procedencia y la intencionalidad con que fueron hechas las fuentes ${ }^{33}$. La hermenéutica o interpretación de fuentes consiste en el proceso de atribución de sentido a las acciones o interacciones humanas que son objeto de análisis por parte del historiador.

\footnotetext{
${ }^{28}$ Hans Ulrich Gumbrecht, En 1926. Viviendo al borde del tiempo (México: Universidad Iberoamericana, $2004), 416$.

${ }^{29}$ Hablamos de hecho histórico atendiendo a la distinción hecha por Hayden White entre hecho histórico y acontecimiento histórico: “...distingo un acontecimiento (como un acontecer que sucede en un espacio y un tiempo materiales) y un hecho (un enunciado acerca de un acontecimiento)". Hayden White, El texto histórico como artefacto literario y otros escritos (Barcelona: Paidós, 2003), 53.

${ }^{30}$ Febvre, Combates..., 24.

${ }^{31}$ White, El texto histórico..., 207.

${ }^{32}$ González, Otra invitación ..., 45-47.

${ }^{33}$ González, Otra invitación ..., 47.
} 
En lo que concierne a la heurística, a la búsqueda de las mejores fuentes disponibles para realizar una investigación -dependiendo del punto de vista o enfoque para abordar el problema de investigación-, en primer término, vale la pena mencionar que no hay prácticamente ninguna huella del acontecer que carezca intrínsecamente de valor para una comunidad de historiadores, especialmente después de los planteamientos de la Escuela de los Annales. Como lo señala enfáticamente Lucien Febvre:

Indudablemente la historia se hace con documentos escritos. Pero también puede hacerse, debe hacerse, sin documentos escritos si estos no existen [...] Por tanto, con palabras. Con signos. Con paisajes y con tejas. Con formas de campo y malas hierbas. Con eclipses de luna y cabestros. Con exámenes periciales de piedras realizados por geólogos y análisis de espadas de metal realizados por químicos. En una palabra: con todo lo que siendo del hombre depende del hombre, sirve al hombre, expresa al hombre, significa la presencia, la actividad, los gustos y las formas de ser del hombre ${ }^{34}$.

En segundo término, hay que decir que buena parte de los historiadores de oficio reconocen que los acontecimientos históricos son complejos, tienen múltiples determinaciones $\mathrm{y}$, por tanto, solo pueden ser comprendidos o explicados integralmente combinando o buscando complementariedades entre distintas fuentes. Es precisamente en este marco que adquiere importancia, en la investigación histórica, la habilidad para construir representaciones aceptables de los acontecimientos del denominado pasado a partir de fragmentos dispersos. En palabras de Marc Bloch:

Sería una gran ilusión imaginarse que a cada problema histórico responde un tipo único de documentos, especializado en ese empleo. Al contrario, cuanto más se empeña la investigación en llegar a los hechos profundos, menos se le permite esperar la luz sino por rayos convergentes de testimonios de naturaleza muy diversa ${ }^{35}$.

Quienes cultivan la historia como disciplina, con frecuencia aceptan que el historiador debe, además de seleccionar las fuentes, poder establecer, a partir de la crítica de fuentes, por qué llegaron a existir los materiales con los cuales trabaja, quiénes son en realidad sus autores, cuándo fueron producidos, en dónde y con qué intenciones. En efecto, en esta labor de crítica de fuentes, el historiador contrasta unas fuentes con otras y examina con detalle las condiciones en las que estas se produjeron:

\begin{abstract}
Se trate de documentos conscientes o inconscientes (huellas dejadas por los hombres más allá de toda voluntad de dejar un testimonio a la posteridad), las condiciones de producción del documento tienen que ser cuidadosamente estudiadas. En efecto, las estructuras de poder de una sociedad incluyen la facultad que tienen las categorías sociales y grupos dominantes de dejar, voluntaria o involuntariamente, testimonios susceptibles de orientar la historiografía en este u otro sentido. El poder sobre la memoria futura, el poder de perpetuación, tiene que ser reconocido y descifrado por el historiador. Ningún documento es inocente. Debe ser juzgado. Todo documento es un monumento que hay que saber desestructurar, desmontar. El historiador no solo tiene que saber discernir la falsedad, evaluar la credibilidad de un documento, tiene que desmitificarlo ${ }^{36}$.
\end{abstract}

En tercer lugar, el historiador debe analizar e interpretar la información contenida en las fuentes. En palabras de Marc Bloch, el análisis consiste en clasificar y ordenar ${ }^{37}$, a partir

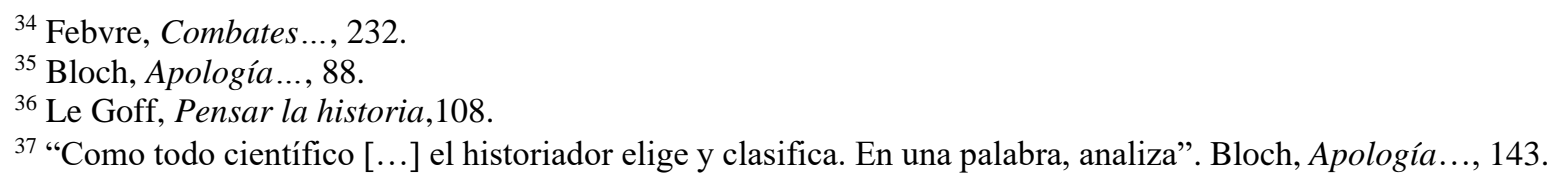


de categorías, la información contenida en las fuentes. Por su parte, la interpretación consiste en identificar redes de relaciones entre los datos empíricos, insertándoles en una serie cronológica o en un conjunto sincrónico ${ }^{38}$. Entonces, ambos procesos, el análisis y la interpretación, exigen al historiador poner en juego habilidades de abstracción e imaginación conducentes a construir unidades, conjuntos y series que permitan describir de la mejor manera posible las relaciones entre cada uno de los elementos objeto de análisis. Tal y como lo señala George Duby, "el historiador debe elegir entre distintas interpretaciones aquella que mejor le permite representar las relaciones entre los elementos que son objeto de su análisis" 39 y el historiador "modela para hacer coherente un conjunto de datos dispersos"

En síntesis, como lo plantean distintos investigadores cuyos trabajos se fundamentan en tradiciones historiográficas diversas, la historiografía se construye con documentos, pero no se agota en ellos:

Creer que la nomenclatura de los documentos es suficiente para fijar la nuestra implicaría, finalmente, admitir que estos nos estregan el análisis ya elaborado. La historia, en tal caso, no tendría mucho que hacer. Felizmente y para nuestra satisfacción no es así. Es por ello que nos vemos obligados a buscar en otra parte nuestras grandes líneas de clasificación ${ }^{41}$.

Si bien los hechos están relatados, inscritos en el registro histórico, es necesario que el historiador devele sus significados y sus relaciones, es decir, el conocimiento histórico, "por sí mismos, e independientemente de todo tratamiento teorético" ${ }^{42}$. Porque como argumenta Foucault:

El documento no es, pues, para la historia, esa materia inerte a través de la cual trata esta de reconstruir lo que los hombres han hecho o dicho, lo que ha pasado y de lo cual solo resta el surco: el historiador trata de definir en el propio tejido documental unidades, conjuntos, series, relaciones ${ }^{43}$.

Y precisamente ahí está la función del historiador: dar vida a los documentos a través del análisis; concatenar los hechos encontrados en las fuentes históricas; plasmar una realidad inmersa en los documentos con el debido análisis que permita profundizar en esa realidad, no solo conocerla sino también proyectarla a otras situaciones históricas similares.

\section{De los usos y límites de la historiografía}

En conjunto, los trabajos de reflexión sobre el oficio del historiador, examinados en las secciones precedentes, permiten constatar que son múltiples los usos posibles de la historia. En efecto, se puede hacer historia para comprender los sistemas de valores y las prácticas de los seres humanos, para esclarecer qué condiciones hicieron posible un determinado hecho o acontecimiento, para comprender el presente y la manera como hemos llegado a ser lo que somos, para generar conciencia social sobre un problema o una determinada realidad que afecta a un grupo de personas e, incluso, se puede hacer historia

\footnotetext{
38 "En efecto, nunca se restablece una fecha, ni se controla, ni finalmente se interpreta un documento, sino insertándolo en una serie cronológica o en un conjunto sincrónico". Bloch, Apología..., 120.

${ }^{39}$ Georges Duby, La historia continua (Madrid: Editorial Debate S.A, 1992), 65-66.

${ }^{40}$ Duby, La historia continua, 74.

${ }^{41}$ Bloch, Apología ...,160.

42 Thompson, La miseria..., 51.

${ }^{43}$ Michel Foucault, La arqueología del saber (México: Siglo XXI, 1970), 10.
} 
para evitar que se fetichicen o petrifiquen las interpretaciones construidas por los historiadores.

Por mencionar solo algunos ejemplos, puede hacerse historia para "hacer más rica y más lúcida la consciencia que los hombres tienen de su situación" 44 , "para comprender los fines que orientan las acciones de los seres humanos"45, "para exhumar hechos que habían caído en el olvido o de los que nadie había sido nunca consciente"46, "para situar el momento actual en el devenir" 47 " "para hacer presente el pasado" 48 , "para construir nuevas y diferentes interpretaciones de los hechos" 49 , "para averiguar no solo por lo que ocurrió, sino también por cómo pudo suceder"50.

En cualquier caso, y esta es una premisa aceptada por buena parte de la comunidad de historiadores, el conocimiento producido en el marco y bajo las reglas de la ciencia histórica conserva una distancia relativa con respecto a la memoria social, a los usos que las personas y los grupos sociales hacen del acontecer. "Hay por lo menos dos historias: la de la memoria colectiva y la de los historiadores" ". Si bien la sociedad vivencia sus costumbres, tradiciones, memorias e historias, es el historiador quien debe esforzarse en comprenderlas a través del análisis ${ }^{52}$ :

... habría que tener en cuenta la influencia de la historia sobre la memoria, ya que no existe memoria literal originaria y no contaminada: los recuerdos son constantemente elaborados por una memoria inscrita en el espacio público, sometidos a los modos de pensar colectivos, pero también influidos por los paradigmas científicos de la representación del pasado. Esto ha dado lugar a unos híbridos que permiten a la memoria revisitar la historia subrayando sus ángulos muertos y sus generalizaciones apresuradas, y a la historia corregir las trampas de la memoria obligándola a transformarse en análisis autorreflexivo y en discurso crítico ${ }^{53}$.

En lo que respecta a los límites de la historiografía como práctica, hay dos acuerdos más o menos generales entre los historiadores de oficio: el conocimiento sobre los denominados hechos del pasado es complejo, y es provisional. Complejo, porque hoy, como nunca, se reconoce que los acontecimientos históricos no tienen una causa única; provisional porque, como lo mencionamos al inicio de este escrito, se concibe la historiografía como el resultado de una delimitación y como un conocimiento susceptible de múltiples revisiones:

No creemos ya, por tanto, en la explicación de la historia por este u otro factor dominante. No hay historia unilateral. No la dominan en exclusiva ni el conflicto ni las razas [...] ni los poderosos ritmos económicos, factores de progreso o de caos; ni las constantes tensiones sociales [...] ni el reino de la técnica; ni la presión demográfica [...] el hombre es mucho más complejo ${ }^{54}$.

${ }^{44}$ Josep Fontana, La historia después del fin de la historia (Barcelona: Editorial Crítica, 1992), 78.

45 González, Otra invitación ..., 77.

${ }^{46}$ Pomian, Sobre la historia, 212.

${ }^{47}$ Aron, Dimensiones de la conciencia histórica, 15.

${ }^{48}$ Gumbrecht, En 1926..., 413.

${ }^{49}$ Aguirre, Antimanual del mal historiador..., 24.

${ }^{50}$ Koselleck, Los estratos del tiempo..., 39.

${ }^{51}$ Le Goff, Pensar la historia, 31.

${ }^{52}$ Aron, Dimensiones de la conciencia histórica, 20.

${ }^{53}$ Enzo Traverso, El pasado, instrucciones de uso: historia, memoria, política (Madrid: Marcial Pons, 2007), 29-30.

${ }^{54}$ Braudel, La historia ..., 25-26. 
De igual forma, hay un reconocimiento relativamente amplio de los límites de las fuentes con que trabaja el historiador, de los límites de los testimonios orales para dar cuenta de los procesos de media y larga duración, de los límites de ciertas fuentes para dar a conocer las prácticas de los seres humanos en su devenir y, en general, de los límites de utilizar un conjunto de evidencias restringidas para dar parte de fenómenos complejos. Como señala Braudel:

A los ojos de los contemporáneos los hechos se presentan, por desgracia con excesiva frecuencia, en un mismo plano de importancia; y los muy grandes acontecimientos constructores de futuro hacen tan poco ruido-llegan en patas de tórtola, decía Nietzsche- que es difícil adivinar su presencia ${ }^{55}$.

El historiador debe analizar y rastrear los distintos factores que explican o contribuyen a la comprensión de un suceso, pues estos "no son idénticos a los motivos o los pretextos que los hombres aducen" 56 . Por lo demás, entre los historiadores hay un reconocimiento cada vez más amplio de los límites impuestos por la historiografía misma:

\begin{abstract}
Antes que saber lo que la historia dice de una sociedad, importa analizar cómo funciona en ella. Esta institución se inscribe en un complejo que le permite solo un tipo de producciones y le prohíbe otros. Tal es la doble función del lugar, del ámbito. Posibilita ciertas investigaciones, gracias a coyunturas y problemáticas comunes. Pero imposibilita otras; excluye del discurso aquello que, en un momento dado, es su condición; desempeña el papel de una censura con respecto a los postulados presentes (sociales, económicos, políticos) del análisis. Esta combinación entre la permisión y la interdicción es, sin duda, el punto ciego de la investigación histórica, y la razón por la que no es compatible con cualquier $\operatorname{cosa}^{57}$.
\end{abstract}

Por tanto, para hacer historiografía es necesario que el historiador vea más allá del documento, escuche con detenimiento la fuente oral y se sumerja en un análisis que permita reconstruir el devenir o el denominado "pasado", conocer las situaciones que llevan a un suceso, pero sin estar inmiscuido en él y que, por consiguiente, la esencia de la historia se pierda por los afectos o resentimientos humanos puestos por quien se dedique a su estudio.

\title{
Sobre la naturaleza del conocimiento de lo histórico
}

El análisis de las reflexiones de los historiadores sobre su oficio permite identificar también un conjunto de acuerdos básicos en torno a la naturaleza o al tipo de conocimiento que se produce en el campo de la historia. En general, los historiadores coinciden en que el conocimiento histórico tiene pretensiones de veracidad, es verificable, indirecto, inacabado, contemporáneo, contextual, complejo y susceptible de comparación.

En primer término, el conocimiento de lo histórico es concebido como un conocimiento que tiene pretensiones de veracidad, que provee interpretaciones soportadas en documentos $^{58}$; que parte de una evaluación crítica de las fuentes y aspira a mostrar una imagen verdadera de lo que ocurrió, de los acontecimientos, "porque para ser válido, cualquier discurso sobre la historia ha de ser a su vez un discurso histórico"

En segundo término, el conocimiento es concebido como un conocimiento verificable, sujeto a discusión, construido colectivamente y susceptible de ser examinado y

\footnotetext{
${ }^{55}$ Braudel, La historia ..., 49.

${ }^{56}$ Koselleck, Los estratos del tiempo ..., 74.

${ }^{57}$ De Certeau, "La operación histórica”, 31.

58 "Un historiador, desde su condición de historiador, solo puede afirmar aquello que puede demostrar". Pomian, Sobre la historia, 258.

${ }^{59}$ Pomian, Sobre la historia, 61.
} 
replicado por una comunidad de historiadores ${ }^{60}$. En una dirección similar, se concibe el conocimiento de lo histórico como inacabado, perfectible, probable, susceptible de revisión, siempre incompleto frente a la complejidad de las realidades históricas. De igual forma, se caracteriza el conocimiento de lo histórico como contextual. De una parte, porque se produce tomando como referencia unas condiciones espaciotemporales específicas ${ }^{61}$. De otra parte, porque se trata de un conocimiento sobre un conjunto de acontecimientos que tuvieron lugar en un espacio social identificable y en el marco de unas condiciones sociales específicas.

El discurso científico que no habla de su relación con el cuerpo social no puede articular una praxis. Deja de ser científico. Y este problema es central para el historiador. Esta relación al cuerpo social es precisamente el objeto de la historia. Y no puede abordarse sin poner igualmente en tela de juicio el mismo discurso historiográfico ${ }^{62}$.

Además de ello, se concibe la historiografía como una práctica siempre contemporánea, en sí misma histórica, que expresa un diálogo sobre el acontecer (reconocido como presente, pasado y futuro). Se encuentra marcada de manera inequívoca por la experiencia histórica de quienes la hacen porque “... historia e historiografía, la realidad y su procesamiento consciente están siempre complicados, se justifican recíprocamente, sin ser absolutamente derivable uno de otro"63.

En último término, en esta perspectiva del oficio del historiador, es preciso considerar que se caracteriza el conocimiento producto de la investigación histórica como un conocimiento no accesible a la consciencia del hombre en su cotidianidad y como un conocimiento complejo, sensible a las determinaciones múltiples de los hechos históricos. En tanto no accesible al hombre en su cotidianidad, el conocimiento implica una operación histórica, un esfuerzo metodológico y operativo tendiente a transformar una experiencia histórica de un grupo de hombres en un tema o temas de conocimiento ${ }^{64}$. En lo que se refiere a la complejidad, el conocimiento de lo histórico implica atender a las redes de relaciones en que se tejen los hechos, implica una reflexión sobre las posibilidades y límites de uso del concepto de causa en el campo de la historia, al respecto afirma P. Vilar:

... en historia desconfío de la noción de causa, generalmente simplificadora, e incluso de la noción de factor (salvo si puede ser matematizado en tal o cual terreno). Prefiero hablar de componentes de una situación, elementos de naturaleza sociológica con frecuencia distinta, que se convivan en relaciones siempre recíprocas pero variables en los orígenes, en el desarrollo, en la maduración de dichas situaciones ${ }^{65}$.

\footnotetext{
${ }^{60}$ Pomian, quien entiende por marcas de historicidad aquellas evidencias a partir de las cuales se legitima el trabajo historiográfico, señala lo siguiente al respecto: "Las marcas de historicidad que aparecieron en la época moderna sirven precisamente para hacer posible una repetición-reproducción del trabajo del historiador, autor de un texto, por parte de otro historiador que tenga las competencias adecuadas" Pomian, Sobre la historia, 81. 61 "Pero el historiador no se mueve en la abstracción: si bien no rechaza las sugerencias de ninguna ciencia humana, necesita comprobar su aplicación en el espacio y el tiempo" Pierre Vilar, Pensar la historia (México: Instituto Mora, 1992), 24.

${ }^{62}$ De Certeau, "La operación histórica", 23.

${ }^{63}$ Koselleck, Los estratos del tiempo..., 48.

64 "Si aceptamos que un acontecimiento es un cambio percibido, la historia, la historia económica y social en particular, en la medida en que se desvía del contenido explícito de las narraciones, pasa por alto los acontecimientos en beneficio de los hechos que los historiadores reconstruyen a partir de los contenidos latentes, de los elementos repetitivos y de las huellas". Pomian, Sobre la historia, 213.

${ }^{65}$ Vilar, Pensar la historia, 25.
} 
Desde luego, lo anterior tiene consecuencias para el historiador, pues las causas de un fenómeno son irreductibles a los motivos expresados por los actores de la historia y, en todos los casos, desde su perspectiva, sería necesario entender los fenómenos históricos en una dialéctica entre los elementos sincrónicos y diacrónicos del acontecer.

\section{A modo de cierre: ¿una historia inconclusa?}

En su lúcida reflexión sobre la historia K. Pomian señala que "la historia solo puede dar el máximo de sí misma si es al mismo tiempo una ciencia que establece los hechos, un arte de presentarlos y una filosofía que permite comprenderlos". En las páginas precedentes se hizo un balance del oficio del historiador como práctica científica, como arte y como disciplina orientada a hacer inteligible lo acontecido mediante procedimientos y supuestos compartidos por la comunidad de historiadores. Sin embargo, el quehacer historiográfico exige imaginación, sensibilidad, sentido de responsabilidad y compromiso político.

Hay que considerar entonces la historia "como una práctica científica, sin perder de vista su rol en la sociedad", teniendo en cuenta que en la sociedad en la que vivimos -la sociedad del conocimiento y la información- la cultura histórica y el valor social atribuido al conocimiento sobre lo acontecido, sin lugar a dudas, es ambivalente. Por un lado, como señala Gumbrecht, pocos parecen tener interés en apoyarse en el conocimiento del pasado para resolver situaciones prácticas, pocos consideran la historia como un campo sólido para apoyar decisiones cotidianas ${ }^{66}$. En contraste, Pomian afirma:

La revolución de los medios de comunicación permite al parecer revivir el pasado, volver a sus escenas y oír sus sonidos, siempre y cuando hayan sido grabados; porque, al conferirle al pasado una dimensión sensible de la que antes carecía, lo ha convertido en un objeto de una casi percepción ${ }^{67}$.

Para afrontar este escenario en el cual el saber sobre lo acontecido pierde en alguna medida su facultad de orientar la acción humana hacia un futuro prometedor ${ }^{68}$, pero adquiere una nueva visibilidad mediática, se hace imprescindible tanto imaginar nuevas formas de usar el conocimiento histórico disponible como reflexionar sobre aquello que nos impulsa hacia las realidades pasadas. Ensayando una respuesta a este último interrogante Gumbrecht sugiere, por ejemplo, que lo que nos impulsa hacia el pasado no es necesariamente la intención de resolver problemas del presente, sino un genuino deseo de traspasar "la frontera que separa nuestras vidas del tiempo que transcurrió antes de nuestro nacimiento"69. En últimas, "un deseo de tener una experiencia inmediata del pasado"

En cualquier caso, como bien lo precisa Pomian:

La redacción por parte de los historiadores de manuales escolares y de libros de difusión y su participación en la programación de conmemoraciones y en emisiones de radio y televisión, todas estas

\footnotetext{
${ }^{66}$ Gumbrecht, En 1926..., 399.

${ }^{67}$ Pomian, Sobre la historia, 217.

68 “... desde que se ha desvanecido el entusiasmo con respecto al concepto de progreso, el futuro se ha vuelto otra vez algo amenazador: ahora está habitado por imágenes de catástrofes nucleares y de la polución de nuestro entorno natural, el exceso de población y la expansión de epidemias”. Gumbrecht, En 1926..., 408.

${ }^{69}$ Gumbrecht, En 1926..., 406.

${ }^{70}$ Gumbrecht, En 1926..., 409.
} 
actividades se sitúan en la frontera entre la historia erudita y la memoria colectiva o, mejor aún, en un espacio que pertenece unas veces a una y otras a otra, $y$ otras a ambas a la vez ${ }^{71}$.

Dadas estas condiciones, la tendencia sería entonces un incremento cada vez más sustantivo de las intersecciones entre la historiografía y la memoria social, entre la producción de conocimiento especializado sobre la historia y la manera como los grupos o miembros de una sociedad recuerdan los hechos históricos.

Finalmente, la historia puede jugar un rol relevante en la sociedad si se asume como un oficio que permite recordar aquello que no deja huellas en la memoria colectiva ${ }^{72}$; si se constituye en un esfuerzo por devolver la historicidad a aquello que se ha objetivado ${ }^{73}$; si se encarga de desmitificar las explicaciones consagradas y comunes repetidas una y otra vez en la historiografía. En suma, si permite que las personas puedan reconocer que, independientemente del rumbo que tome un suceso, siempre hay varios futuros alternativos:

Un buen historiador genuinamente crítico, nos recuerda siempre que ayer igual que hoy, la historia es un terreno de disputa constante, donde de manera contradictoria y tenaz se enfrentan siempre varios futuros alternativos posibles, varias líneas abiertas de posibles evoluciones diferentes, y en donde la línea o futuro que resulta finalmente vencedor y que se actualiza, se decide justamente desde y dentro de las condiciones concretas de ese espacio de combate ${ }^{74}$.

Con base en lo expuesto a lo largo de este escrito, es preciso señalar que hoy el oficio del historiador implica una reflexión permanente sobre la práctica; un reconocimiento de la producción historiográfica como una obra colectiva; una habilidad para reconocer las condiciones económicas, políticas, sociales y culturales que inciden en la producción historiográfica; flexibilidad para explorar las distintas alternativas de abordaje del tiempo histórico; capacidad para identificar distintos usos de una misma fuente y para identificar complementariedades entre fuentes de distinto tipo; disposición para valorar las posibilidades y límites de una fuente; criterios para organizar y clasificar información proveniente de distintas fuentes y para establecer relaciones entre hechos o fenómenos que son contiguos en el tiempo; capacidad para examinar la evolución histórica de un fenómeno o problema e imaginación para e identificar los distintos usos posibles del conocimiento histórico.

El campo de la historia ha mostrado una gran apertura y el oficio del historiador se ha hecho mucho más complejo. En adelante, sin duda, para el historiador será cada vez más difícil afrontar su oficio sin construir con otros historiadores proyectos historiográficos convergentes y socialmente relevantes; sin dialogar con la memoria colectiva y con la cultura histórica; sin atender a la complejidad temporal de los fenómenos; sin advertir las discontinuidades y al cambio histórico y sin transitar con cierta fluidez entre las dimensiones sincrónicas y diacrónicas de los hechos históricos. En suma, sin concebir su oficio como un proyecto interminable, pero con profundas consecuencias sobre el propio pensamiento y

\footnotetext{
${ }^{71}$ Pomian, Sobre la historia, 218.

72 "La historia exhuma hechos que habían caído en el olvido y otros de los que nadie había sido nunca consciente y que por ello había permanecido fuera de la memoria”. Pomian, Sobre la historia, 212.

${ }^{73}$ Dice Le Goff citando a Witold Kula: "El historiador tiene que luchar paradójicamente contra la fetichización de la historia [...]. La edificación de la fuerza histórica, que lleva a un sentimiento generalizado de impotencia e indiferencia, se convierte en un verdadero peligro social; el historiador tiene que reaccionar, mostrando que nunca nada está inscrito por anticipación en la realidad, y que el hombre puede modificar las condiciones que se le han impuesto" Le Goff, Pensar la historia, 141.

${ }^{74}$ Aguirre, Antimanual del mal historiador..., 33.
} 
sobre la vida de los hombres. Como plantea Marc Bloch "el pasado es por definición algo dado que ya no será modificado por nada. Pero el conocimiento del pasado es una cosa en progreso que no deja de transformarse y perfeccionarse" ${ }^{75}$.

${ }^{75}$ Bloch, Apología ..., 82. 


\section{Referencias}

Aguirre, Carlos Antonio. Antimanual del mal historiador: o ¿cómo hacer hoy una buena historia crítica? México: Editorial Contrahistorias, 2005.

Aron, Raymond. Dimensiones de la conciencia histórica. Madrid: Tecnos S.A., 1982.

Aróstegui, Julio. La investigación histórica: teoría y método. Barcelona: Crítica, 1995.

Bloch, Marc. Apología para la historia o el oficio de historiador. México. Fondo de Cultura Económica, 2001.

Braudel, Fernand. La historia y las ciencias sociales. Madrid: Alianza, 1970.

Collingwood, Robin George. Idea de la historia. México: Fondo de Cultura Económica, 1952.

De Certeau, Michel. "La operación histórica”. En Hacer la historia. Nuevos problemas, compilado por Jacques Le Goff y Pierre Nora. Barcelona: Editorial Laia, 1978.

Duby, Georges. La historia continua. Madrid: Editorial Debate S.A, 1992.

Febvre, Lucien. Combates por la historia. Barcelona: Ariel, 1982.

Fontana, Josep. La historia después del fin de la historia. Barcelona: Editorial Crítica, 1992.

Foucault, Michel. La arqueología del saber. México: Siglo XXI, 1970.

González, Luis. Otra invitación a la microhistoria. México D.F.: Fondo de Cultura Económica, 2003.

Gumbrecht, Hans Ulrich. En 1926. Viviendo al borde del tiempo. México: Universidad Iberoamericana, 2004.

Koselleck, Reinhart. Los estratos del tiempo: estudios sobre la historia. Barcelona: Paidós, 2001.

Le Goff, Jacques. Pensar la historia. Barcelona: Editorial Altaya, 1995.

Pomian, Krzysztof. Sobre la historia. Madrid: Ediciones Cátedra, 2007.

Thompson, Edward P. La miseria de la teoría. Barcelona: Crítica, 1981.

Traverzo, Enzo. El pasado, instrucciones de uso: historia, memoria, política. Madrid: Marcial Pons, 2007.

Vilar, Pierre. Pensar la historia. México: Instituto Mora, 1992. 
White, Hayden. El texto histórico como artefacto literario y otros escritos. Barcelona: Paidós, 2003. 